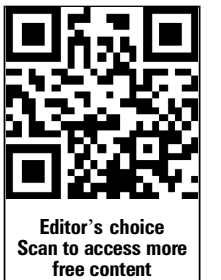

free content

- Additional material is published online only. To view please visit the journal online (http://dx.doi.org/10.1136/jech2013-202843).

${ }^{1}$ Faculty of Language and Literature, Humanities, Arts and Education, University of Luxembourg, Walferdange, Luxembourg

${ }^{2}$ Department of Social Policy, London School of Economics and Political Science, LSE Health and Social Care, London, UK

${ }^{3}$ Department of Social and Behavioral Sciences, Harvard School of Public Health,

Boston, Massachusetts, USA

\section{Correspondence to}

Dr Anja K Leist,

Faculty of Language and

Literature, Humanities,

Arts and Education, University

of Luxembourg, Route de

Diekirch, Walferdange L-7220,

Luxembourg;

anja.leist@uni.lu

Received 9 May 2013

Revised 17 September 2013

Accepted 18 September 2013

Published Online First

4 November 2013

\title{
Do economic recessions during early and mid-adulthood influence cognitive function in older age?
}

\author{
Anja K Leist, ${ }^{1}$ Philipp Hessel, ${ }^{2}$ Mauricio Avendano ${ }^{2,3}$
}

\begin{abstract}
Background Fluctuations in the national economy shape labour market opportunities and outcomes, which in turn may influence the accumulation of cognitive reserve. This study examines whether economic recessions experienced in early and mid-adulthood are associated with later-life cognitive function.

Method Data came from 12020 respondents in 11 countries participating in the Survey of Health, Ageing and Retirement in Europe (SHARE). Cognitive assessments in 2004/2005 and 2006/2007 were linked to complete work histories retrospectively collected in 2008/2009 and to historical annual data on fluctuations in Gross Domestic Product per capita for each country. Controlling for confounders, we assessed whether recessions experienced at ages 25-34, 35-44 and 45-49 were associated with cognitive function at ages $50-74$.
\end{abstract}

Results Among men, each additional recession at ages 45-49 was associated with worse cognitive function at ages $50-74(b=-0.06, C l-0.11$ to -0.01$)$. Among women, each additional recession at ages $25-44$ was associated with worse cognitive function at ages $50-74$ $\left(b_{25-34}=-0.03, \mathrm{Cl}-0.04\right.$ to $-0.01 ; b_{35-44}=-0.02, \mathrm{Cl}$ -0.04 to -0.00 ). Among men, recessions at ages 45-49 influenced risk of being laid-off, whereas among women, recessions at ages 25-44 led to working parttime and higher likelihood of downward occupational mobility, which were all predictors of worse later-life cognitive function.

Conclusions Recessions at ages 45-49 among men and 25-44 among women are associated with later-life cognitive function, possibly through more unfavourable labour market trajectories. If replicated in future studies, findings indicate that policies that ameliorate the impact of recessions on labour market outcomes may promote later-life cognitive function.

\section{INTRODUCTION}

Midlife labour market outcomes and working conditions have been shown to predict cognitive function and decline at older age. Occupational class, ${ }^{1-4}$ longer working hours, ${ }^{5}$ occupational solvent exposures, career trajectories ${ }^{367}$ and occupational complexity at work $^{8-10}$ are all strong predictors of later-life cognitive function. Based on the cognitive reserve framework, ${ }^{11}$ these studies hypothesise that working conditions influence the potential to build up cognitive reserve, which in turn influences cognitive performance at later ages. These studies are, however, prone to selection bias, because higher cognitive function may select individuals into more favourable occupations and working environments.
For example, previous research suggests that subtle differences in cognitive function early in life may lead to divergent career trajectories. ${ }^{12}$ A potential alternative to address this bias is to examine how macroeconomic 'shocks', which can be viewed as largely exogenous to the cognitive function of the working population, relate to later-life cognitive outcomes. The rationale for this approach is that cohorts affected by negative, unanticipated macroeconomic shocks at vulnerable points in their life course may have less potential to build up cognitive reserve. These effects, however, would be unrelated to their early life characteristics or other individual factors that affect their individual labour market and cognitive function trajectories.

This hypothesis is supported by prior evidence that economic hardship during early childhood is associated with lower cognitive function in older age, in particular if additional disadvantages come into play. ${ }^{13}$ Similarly, recent evidence suggests that being born during a recession is significantly associated with lower later-life cognitive function. ${ }^{14}$ No studies have yet explored whether recessions experienced during working ages may have cumulative effects on cognitive function at older ages. To our knowledge, this is the first study to adopt a life course perspective to assess whether macroeconomic fluctuations experienced during working ages are associated with later cognitive function and to investigate some of the potential labour market mechanisms that may explain this association.

Macroeconomic conditions during working ages may influence accumulation of cognitive reserve through unfavourable working conditions and opportunities in terms of social mobility. In support of this view, evidence indicates that economic recessions experienced in the year of transition from school to work are associated with less favourable career trajectories, higher job instability, reduced earnings and less favourable working conditions in midlife. ${ }^{15-17}$ So far, no studies have examined whether these working conditions affected by labour market fluctuations around these vulnerable ages may also have long-lasting and permanent negative associations with cognitive function at older age.

In this article, we examine whether economic recessions experienced in early and mid-adulthood are associated with later-life cognitive function. We assessed exposure to recessions during early age (25-34), midage (35-44) and late middle adulthood (45-49) covering the years prior to retirement and related this to cognitive assessments at ages 50-74 in a sample of Europeans in 11
Avendano M. J Epidemiol

Community Health

2014;68:151-158 
countries. Based on the life course accumulation of advantages and disadvantages framework, ${ }^{18}$ we hypothesised that each additional recession experienced during working ages is associated with worse later-life cognitive function. In addition, we expected recessions experienced during early adulthood to have a stronger association with cognitive function than recessions experienced later in life. To shed light on the potential mechanisms, we also linked data on economic recessions to individuallevel data on full employment histories covering occupational and labour market conditions throughout adulthood. To our knowledge, our study provides the first assessment of how macroeconomic fluctuations during adult life relates to cognitive function in older age.

\section{METHODS}

Data

The Survey of Health, Ageing and Retirement in Europe (SHARE) is a nationally representative survey which has been designed to provide cross-sectional as well as longitudinal information on the health, employment and social conditions of Europeans aged $50+$. Specific details on the survey are available elsewhere. ${ }^{19-23}$ A German internal review board has approved of ethical standards, study design and data collection. ${ }^{19}$

This study is based on data from three waves of SHARE, the last of which contains detailed individual work histories retrospectively collected using the life-grid method. ${ }^{24}$ The total sample included 19473 participants who had enrolled in the study in either $2004 / 2005$ or $2006 / 2007$ and completed the lifehistory interview in 2008/2009 from 11 countries (Sweden, Denmark, Austria, France, Germany, Switzerland, Belgium, the Netherlands, Spain, Italy and Greece) and had worked at least once during their working life. Respondents from the Czech Republic and Poland were not included due to a lack of comparable data on Gross Domestic Product (GDP) before 1990. We further restricted the sample to individuals aged 50-74 at the time of the first interview to prevent selective attrition due to higher prevalence of cognitive impairment at higher ages $(n=14765)$. We excluded individuals with missing information on two or more of the cognitive measures $(n=1345)$, childhood health, education $(n=292)$ or sampling weights $(n=37)$ and those respondents who never worked $(n=1071)$. The final sample included a total of 12020 men and women in 11 countries (see online supplementary appendix table S1).

\section{Cognitive function}

Cognitive function was assessed once at the first time individuals were interviewed based on the indicators verbal fluency (naming as many animals as possible in $1 \mathrm{~min}$ ), immediate recall (immediately recalling as many words as possible from a 10 -word list that had been read out), delayed recall (recalling the ten-word list after a short delay), orientation (asking respondents the correct day of month, day of the week, month and year) and numeracy (assessed by five arithmetical calculation tasks). ${ }^{25-27}$ A summary score of cognitive functioning was built by averaging the z-scores of the five items.

\section{Macroeconomic conditions}

We use historical time-series data on annual GDP per capita ${ }^{28}$ as indicators of economic conditions. Data used for the analysis comprised the years 1959-2003. We separated the cyclical component from the secular trend in the log of GDP per capita for each country using the Hodrick-Prescott Filter with a smoothing parameter of $100 .^{29} 30$ We converted the cyclical component for each country into quartiles of deviation from the GDP trend. To derive information on country-specific booms and recessions over the study period, deviations from the trend in GDP falling in the highest quartile were classified as booms, while deviations falling in the lowest quartile were classified as recessions. ${ }^{14}$ Online supplementary appendix figure S1 illustrates the exemplary sequence of booms and recessions in four countries. This information was linked to individual records from SHARE based on the year at every age since birth and country of residence, resulting in a variable indicating the number of recessions at every single age from year of birth up to age 49 , the age for which comparable information on GDP was available for most individuals. Our analysis focuses on exposure to recessions at ages 25-49, with the earliest exposure of any respondent at age 25 in the year 1959. Exposure to economic fluctuation was summarised based on the number of years lived in booms and recessions at ages 25-34, 35-44 and 45-49.

Comparable data on GDP per capita for all countries was available only until 2003. For 21\% of participants aged $45-49$ $(n=2602)$, data on business cycle for the period after 2003 were therefore missing. We assigned a separate dummy for these respondents in order to incorporate them in the analysis, but excluding these individuals led to similar results.

\section{Individual level controls}

All models include a set of linear splines for 5-year age-groups from age 50 to 74 to relax the assumption of linear aging-related decline in cognitive function. We included controls for being born before or after the World War II (WWII) in 1945 , country of residence and measures of childhood conditions at age 10 to control for circumstances which may have influenced cognitive functioning independently of economic fluctuations, including (1) self-rated health, (2) material deprivation based on items available at the parental home (eg, a fixed bath, water supply or central heating), (3) self-reported diagnosis of major childhood illnesses, (4) occupation of main breadwinner, (5) the number of books at home, (6) self-rated mathematical and (7) language skills. We also controlled for educational attainment (primary or less, secondary or tertiary) based on the International Standard Classification of Education (ISCED) ${ }^{31}$ and for respondents' first occupation, based on four major groups of the International Standard Classification of Occupations (ISCO-88)..$^{32}$

\section{Life course occupational class mobility and working conditions}

Data on employment histories came from the 2008/2009 wave and covered the entire adult life starting from age of leaving full-time education (or age 15 for those without any schooling) until year of interview or exit from the labour market. Using the life-grid History Event Calendar, individuals were asked to report each paid job that lasted for 6 months or more. For each job, participants reported the year the job started; the occupation that best described the job based on the ISCO-88; whether job was part-time or full-time; changes between part-time and full-time during each job spell and year and reason the job ended. We constructed a database indicating every age between 25 and 49 whether an individual was working, and, across 10 -year age categories, indicators of (1) downward occupational class mobility at least once; (2) multiple changes between fulltime and part-time in a single job spell (as opposed to permanently working full-time or part-time); (3) permanently working part-time in a given job; (4) job loss due to lay-off or plant/ office being closed down at least once; (5) employment gaps due to reasons other than lay-off or plant/office being closed 
down. We then linked this information with data on the number of booms and recessions individuals experienced every decade of their life.

\section{Statistical analysis}

All analyses were stratified by gender. We analysed the association between cognitive functioning at ages 50-74 and number of recessions during the age intervals $25-34,35-44$ and 45-49 using linear regression. This approach exploits the fact that economic conditions at ages $25-49$ are to a large extent random since individuals have no direct influence on them. To control for differences across countries that could bias estimates, we estimated a country-fixed effect model exploiting withincountry variation across cohorts. The country-fixed effect thus controls for all unmeasured differences across countries such as institutional characteristics, economic development or levels of cognitive functioning. Estimates can be interpreted as the association of an additional recession at each given age interval on cognitive functioning, controlling for differences across countries. To explore possible mechanisms between economic conditions and later cognitive function, we also used logistic regressions to model the association of economic booms and recessions with occupational class mobility and working conditions at every decade of life, adjusting for all confounders.

We report unstandardised regression coefficients and 95\% CIs. All analyses were conducted using calibrated sampling weights to account for potential selectivity bias generated by unit non-response, sample attrition and mortality. ${ }^{33}$ All analyses were conducted in Stata/SE V.12.1.

\section{RESULTS}

After excluding respondents with missing information, data of a total of 5891 men and 6129 women were included in the analyses. Average number of recessions varied from 0.73 for men at ages 45-49 to 1.33 for women at ages 35-44 (see online supplementary appendix table S1). Number of booms was in no case related to later cognitive function. Figure 1 shows predicted means of cognitive function according to the number of recessions experienced at each decade of life, controlling for country dummies and age. Men experiencing no recession at ages 45-49 had a mean cognitive score of -0.07 at ages $50-74$, compared with -0.12 for those who experienced four or more recessions at those ages. Similarly, women experiencing no recession at ages 25-34 had an average z-score of cognitive functioning of -0.05 at ages 50-74, whereas women having experienced four recessions in this age interval had an average $\mathrm{z}$-score of -0.17 .

Table 1 shows estimates of the association between recessions at different decades of life and z-scores of cognitive function, along estimates for confounders. Being born before WWII is associated with better cognitive scores for women $(b=0.12$, $\mathrm{p}<0.01$ ), but not for men. Higher occupational status of first job is associated with lower cognitive function for men as well as women. Higher education is associated with better cognitive function for both sexes. Worse self-rated skills in language and mathematics as a child are associated with lower cognitive function in men as well as women.

Analyses included an extensive set of confounders and 5-year age splines. Among men, controlling for all confounders, each additional recession during ages 45-49 was associated with worse cognitive function at ages $50-74(b=-0.06$, CI -0.11 to -0.01$)$, while recessions at earlier ages were not associated with cognitive function. Among women, each additional recession at ages 25-34 or 35-44 was associated with worse cognitive function at ages 50 $74\left(b_{25-34}=-0.03\right.$, CI -0.04 to $-0.01 ; b_{35-44}=-0.02$, CI -0.04 to -0.00$)$. See figure 1 for predicted means of cognitive function according to the number of recessions.

Online supplementary appendix table S2 shows frequencies of selected working trajectories for men and women. Downward occupational mobility and job loss due to lay-off or plant closing is equally frequent in men as well as women between ages 25 and 49 (for each decade less than 6\%). Other changes in working conditions are more frequent for women
Figure 1 Predicted means of cognitive function by number of recessions for men and women. The two panels show the predicted z-score of cognitive functioning for men and women conditional on the number of recessions experienced at three different age intervals. Models include dummies for country of residence and the same covariates as in Table 1. Access the article online to view this figure in colour.
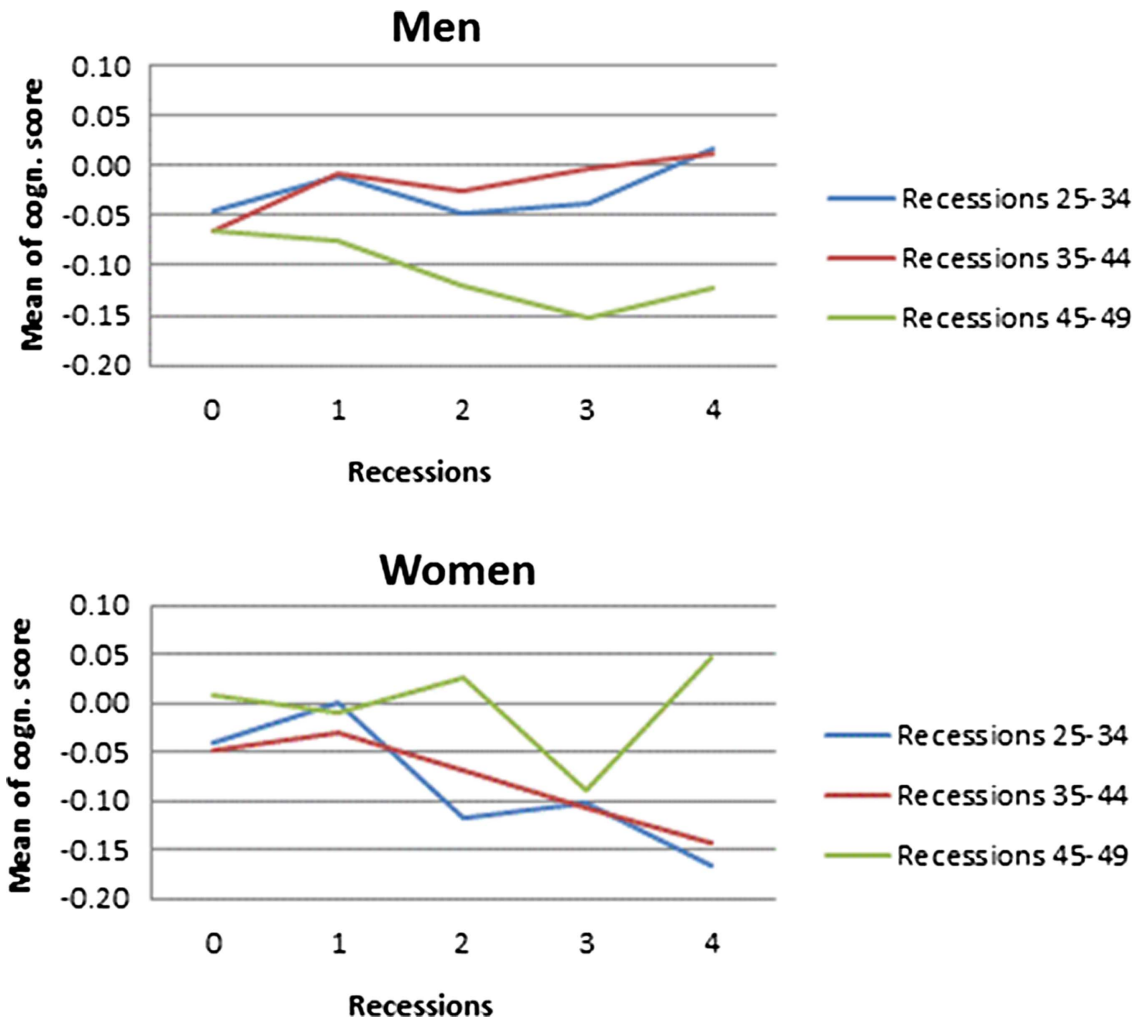
Table 1 Linear Regressions of Number of Recessions at Ages 25-34, 35-44, and 45-49 on Cognitive Function at Ages 50-74, Controlling for First Occupation, Childhood Self-Rated Health, Number of Diseases, Number of Injuries, Number of Mental Conditions, School Performance, Parental Occupation, Number of Books in Parental Household at Age 10, and Education ${ }^{\text {a }}$

\begin{tabular}{|c|c|c|c|c|c|c|}
\hline & \multicolumn{2}{|l|}{ Men } & \multirow[b]{2}{*}{$\mathbf{P}$} & \multirow[b]{2}{*}{ Coeff. } & \multicolumn{2}{|c|}{ Women } \\
\hline & Coeff. & $95 \% \mathrm{Cl}$ & & & $95 \% \mathrm{Cl}$ & $\mathbf{P}$ \\
\hline \multicolumn{7}{|l|}{ Recessions } \\
\hline Ages $25-34$ & 0.01 & $(-0.02,0.04)$ & 0.54 & -0.03 & $(-0.04,-0.01)$ & $<0.01$ \\
\hline Ages 35-44 & -0.01 & $(-0.06,0.04)$ & 0.71 & -0.02 & $(-0.04,-0.00)$ & 0.04 \\
\hline Ages 45-49 & -0.06 & $(-0.11,-0.01)$ & 0.02 & -0.02 & $(-0.05,0.01)$ & 0.11 \\
\hline \multicolumn{7}{|l|}{ Age (Splines) } \\
\hline $50-54$ & 0.19 & $(-0.02,0.39)$ & 0.07 & -0.1 & $(-0.22,0.02)$ & 0.10 \\
\hline $55-59$ & 0.04 & $(-0.04,0.12)$ & 0.30 & -0.03 & $(-0.11,0.05)$ & 0.43 \\
\hline $60-64$ & -0.04 & $(-0.07,-0.00)$ & 0.03 & -0.01 & $(-0.04,0.02)$ & 0.45 \\
\hline $65-69$ & -0.01 & $(-0.04,0.02)$ & 0.49 & -0.04 & $(-0.05,-0.03)$ & $<0.01$ \\
\hline 70-74 & -0.02 & $(-0.04,0.00)$ & 0.11 & -0.02 & $(-0.03,0.00)$ & 0.08 \\
\hline Born before World War II (1945) & 0.04 & $(-0.10,0.17)$ & 0.55 & 0.12 & $(0.06,0.17)$ & $<0.01$ \\
\hline \multicolumn{7}{|l|}{ Early-life socio-economic characteristics } \\
\hline \multicolumn{7}{|c|}{ 1st job International Standard Classification of Occupations (ISCO) (ref.: low skilled blue collar) } \\
\hline High skilled blue collar & 0.03 & $(-0.01,0.07)$ & 0.18 & -0.05 & $(-0.13,0.03)$ & 0.2 \\
\hline Low skilled white collar & -0.11 & $(-0.17,-0.05)$ & $<0.01$ & -0.17 & $(-0.26,-0.09)$ & $<0.01$ \\
\hline High skilled white collar & -0.13 & $(-0.17,-0.08)$ & $<0.01$ & -0.16 & $(-0.22,-0.09)$ & $<0.01$ \\
\hline \multicolumn{7}{|l|}{ Educational level (ref.: primary or less) } \\
\hline Secondary education & 0.18 & $(0.09,0.26)$ & $<0.01$ & 0.22 & $(0.17,0.28)$ & $<0.01$ \\
\hline Post-secondary education & 0.32 & $(0.26,0.38)$ & $<0.01$ & 0.31 & $(0.24,0.38)$ & $<0.01$ \\
\hline \multicolumn{7}{|l|}{ Childhood health } \\
\hline (Very) bad self-rated health as child (ref.: fair or (very) good) & 0.06 & $(-0.00,0.12)$ & 0.06 & -0.04 & $(-0.12,0.04)$ & 0.33 \\
\hline $1+$ infectious disease during childhood & 0.05 & $(-0.01,0.11)$ & 0.09 & 0.03 & $(-0.03,0.10)$ & 0.29 \\
\hline $1+$ physical injury during childhood & -0.12 & $(-0.19,-0.04)$ & 0.01 & 0.01 & $(-0.01,0.03)$ & 0.15 \\
\hline Mental condition during childhood & -0.10 & $(-0.38,0.18)$ & 0.44 & 0.06 & $(-0.05,0.16)$ & 0.25 \\
\hline \multicolumn{7}{|l|}{ No. of books at home (ref.: none or very few $(0-10)$} \\
\hline Enough to fill one shelf (11-25) & 0.10 & $(0.04,0.17)$ & 0.01 & 0.02 & $(-0.03,0.08)$ & 0.37 \\
\hline Enough to fill one bookcase $(26-100)$ & 0.09 & $(0.00,0.19)$ & 0.04 & 0.10 & $(0.04,0.15)$ & $<0.01$ \\
\hline Enough to fill two bookcases (101-200) & 0.24 & $(0.12,0.35)$ & $<0.01$ & 0.11 & $(-0.02,0.23)$ & 0.08 \\
\hline Enough to fill two or more bookcases (more than 200) & 0.24 & $(0.15,0.32)$ & $<0.01$ & 0.12 & $(0.00,0.23)$ & 0.05 \\
\hline \multicolumn{7}{|c|}{ Main occupation of the breadwinner during childhood (ref: low skilled blue collar) } \\
\hline High skilled blue collar & -0.02 & $(-0.10,0.06)$ & 0.52 & 0.00 & $(-0.05,0.05)$ & 0.99 \\
\hline Low skilled white collar & -0.04 & $(-0.14,0.07)$ & 0.45 & -0.02 & $(-0.10,0.07)$ & 0.70 \\
\hline High skilled white collar & 0.03 & $(-0.11,0.17)$ & 0.63 & 0.03 & $(-0.05,0.12)$ & 0.38 \\
\hline \multicolumn{7}{|l|}{ Childhood math-skills compared to peers (ref.: much better) } \\
\hline Better & -0.05 & $(-0.10,-0.01)$ & 0.02 & -0.01 & $(-0.10,0.08)$ & 0.84 \\
\hline About the same & -0.16 & $(-0.21,-0.11)$ & $<0.01$ & -0.14 & $(-0.24,-0.05)$ & 0.01 \\
\hline Worse & -0.34 & $(-0.48,-0.21)$ & $<0.01$ & -0.25 & $(-0.40,-0.09)$ & 0.01 \\
\hline Much worse & -0.24 & $(-0.38,-0.10)$ & $<0.01$ & -0.37 & $(-0.50,-0.24)$ & $<0.01$ \\
\hline \multicolumn{7}{|l|}{ Childhood language-skills compared to peers (ref.: much better) } \\
\hline Better & -0.02 & $(-0.09,0.05)$ & 0.48 & -0.05 & $(-0.11,-0.00)$ & 0.04 \\
\hline About the same & -0.07 & $(-0.13,-0.00)$ & 0.04 & -0.10 & $(-0.16,-0.04)$ & $<0.01$ \\
\hline Worse & -0.09 & $(-0.19,0.00)$ & 0.05 & -0.16 & $(-0.23,-0.09)$ & $<0.01$ \\
\hline Much worse & -0.32 & $(-0.44,-0.20)$ & $<0.01$ & -0.33 & $(-0.44,-0.21)$ & $<0.01$ \\
\hline
\end{tabular}

Abbreviations: Coeff., regression coefficient; $95 \%$ Cl, 95\% confidence interval of double-sided test; P, p-value; WWII, World War II; ISCO, International Standard Classification of Occupations; SRH, self-rated health.

${ }^{a}$ Notes: $\mathrm{N}=12020$. All models include dummies for country of residence (coefficients not shown).

than for men: multiple changes between full-time and part-time work (men $<3 \%$ in each decade, women $7.5-28.1 \%$ ), working part-time (men $<3 \%$, women $21.7-27.8 \%$ ), unemployment due to reasons other than lay-off or plant closing (men 7.8-13.5\%, women 38.2-54.3\%). We first report on the association between each additional recession experienced at each age interval and unfavourable working condition at that same age interval after adjusting for all confounders. Among men, an additional recession experienced at ages 25-34 was not associated with working conditions, while a recession at ages 35-44 was associated with the increased odds of multiple changes between full-time and part-time work in that decade $(\mathrm{OR}=1.15,95 \% \mathrm{CI} 1.05$ to 1.27 ; figure 2$)$. A recession at ages 45-49 was associated with the increased odds of having lost a job due to lay-off or plant/office closure $(\mathrm{OR}=1.73,95 \% \mathrm{CI}$ 1.21 to 2.49 ). Among women, an additional recession at ages 25-34 was associated with worse labour market outcomes for all five indicators (figure 2). 
Men

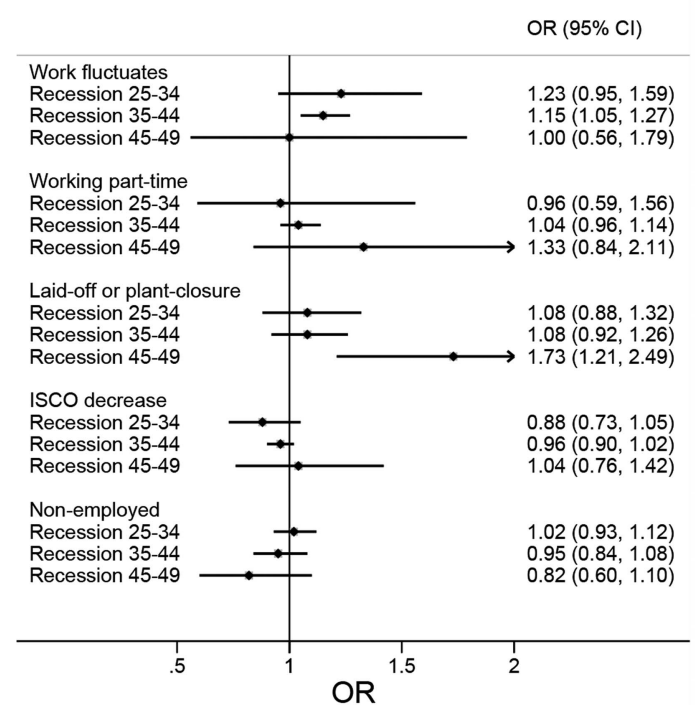

Women

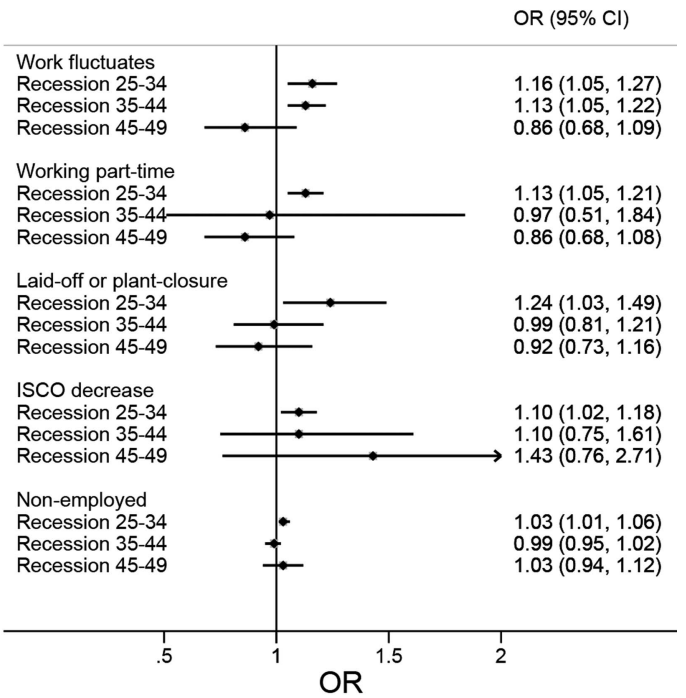

Figure 2 Associations of recessions with working conditions (occupational class mobility and working conditions). The graphs show the ORs of one recession experienced at each age interval on experiencing a respective working condition in this age interval for men and women, after adjusting for all confounders. ORs on the right side of the vertical line indicate an increased likelihood to have experienced one of the five working conditions. All models were run separately for each type of working condition and age interval and include the same individual-level covariates as in table 1 as well as dummies for the country of residence (coefficients not shown). $95 \% \mathrm{Cl}, 95 \% \mathrm{Cl}$ of double-sided test; ISCO, International Standard Classification of Occupations.

Next, we report on the associations of unfavourable working conditions with (lower) cognitive function. For men, job loss due to lay-off or plant/office closure, which was associated with number of economic recessions in that interval, was also associated with worse cognitive function at older age $(b=-0.06, \mathrm{CI}$ -0.01 to -0.02 ; figure 3 ). Among women, of the five indicators that showed an association of additional recessions at ages 25-34, two indicators-working part-time and job loss due to lay-off or plant closure-were in turn associated with significantly lower cognitive function at older age. At ages 35-44, an additional recession was also associated with more job instability as measured by higher odds of changing between full-time and part-time $(\mathrm{OR}=1.13,95 \% \mathrm{CI} 1.05$ to 1.22$)$. Three of the labour market changes at ages $35-44$ in women-working part-

\section{Men}

Women

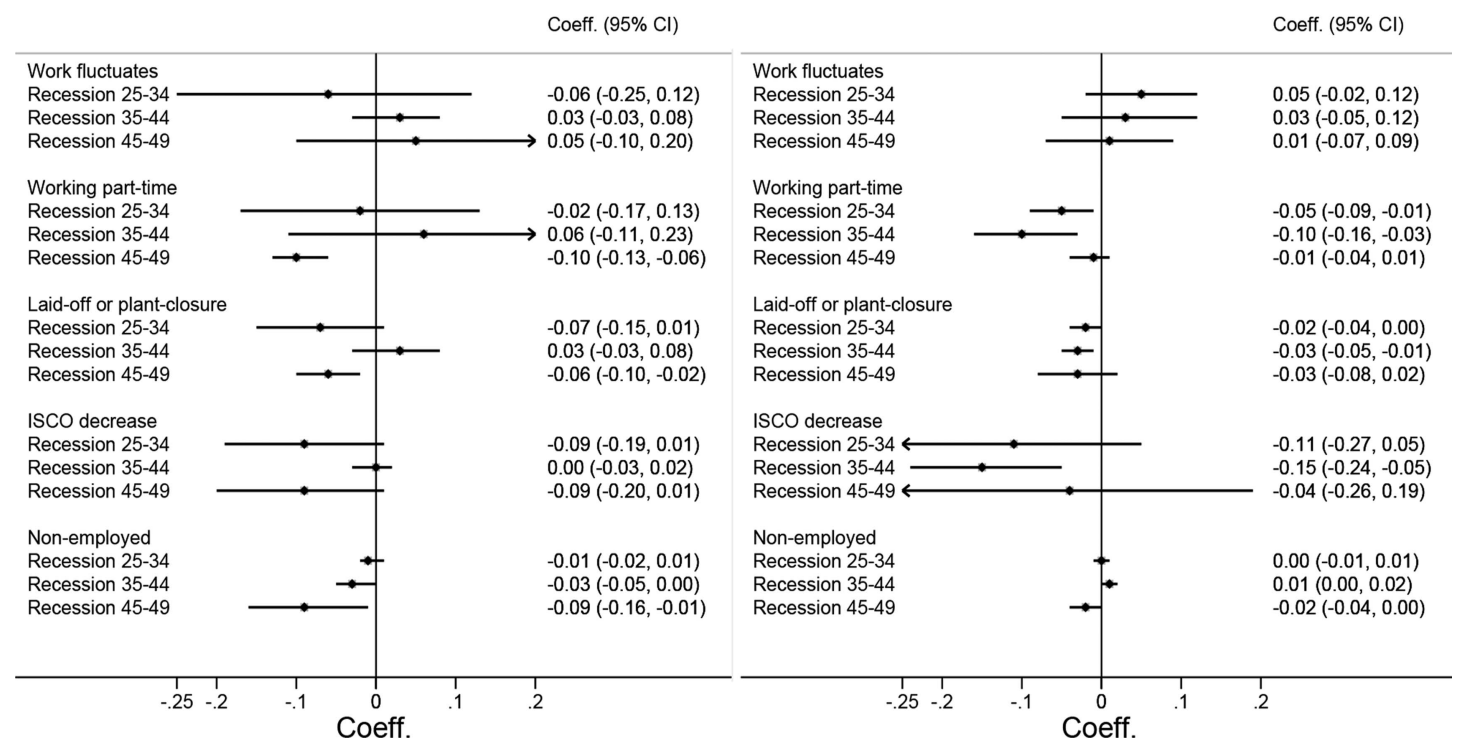

Figure 3 Associations of working conditions and cognitive function for men and women at three age intervals. The graphs show the regression coefficients associated with experiencing a respective working condition in this age interval and cognitive functioning after adjusting for all confounders. All models were run separately for each type of working condition and age interval and include the same individual-level covariates as in table 1 as well as dummies for the country of residence (coefficients not shown). Coeff, regression coefficient; $95 \% \mathrm{Cl}, 95 \% \mathrm{Cl}$ of double-sided test; ISCO, International Standard Classification of Occupations. 
time, losing a job due to plant/office closure or lay-off and downward occupational mobility-were associated with worse late-life cognitive function.

\section{DISCUSSION}

Our study was motivated by previous evidence that working conditions are associated with later-life cognitive function and decline. Our findings provide evidence that economic recessions experienced at vulnerable periods in midlife are associated with decreased later-life cognitive function and that part of this association may operate through the link of recessions with working conditions and labour market trajectories. Men who experienced an additional economic recession at ages 45-49 fared worse cognitive outcomes later in life, which could potentially be due to higher likelihood of job loss due to lay-off or plant closure at these ages. Among women, experiencing an additional recession at ages 25-44 was also associated with poorer cognitive outcomes, which may be explained by their higher rates of job loss due to lay-off or plant/office closure, less stable job careers and higher likelihood of downward occupational mobility associated with recessions.

\section{Explanation of results}

Life course theory suggests that individuals may be more susceptible to environmental influences during certain development stages. ${ }^{18}$ In this regard, our findings provide preliminary evidence on associations between macroeconomic shocks during working life and later-life cognitive function, extending earlier studies on associations between cognitive function at older age and economic conditions during childhood, ${ }^{13} 14$ and associations between later-life cognitive function and contextual level information, such as neighbourhood socioeconomic status, ${ }^{34} 35$ schooling laws ${ }^{36}$ and retirement policies. ${ }^{37}{ }^{38}$ Although more evidence is needed to assess whether associations observed in our study are causal, our findings suggest that potentially unanticipated macroeconomic shocks during vulnerable periods in midlife may affect an individual's potential to accumulate cognitive reserve. A possible explanation is that macroeconomic conditions shape midlife working conditions associated with late-life cognitive function. ${ }^{2-10}$ However, our results suggest that men's susceptibility to macroeconomic shocks may be larger at relatively late stages of the working career, while women are more susceptible to long-run effects on cognitive function if recessions are experienced during early adulthood and mid-adulthood.

Findings for women suggest that early and mid-adulthood recessions are associated with unfavourable changes in working conditions. If causal, this may suggest that the association between economic recessions and cognitive function may operate to some extent through fluctuations in working time, lay-offs and plant closures. Previous evidence suggests that labour market participation among women is strongly influenced by the economic climate, with women during economic downturns being significantly more likely to be out of the labour market ${ }^{39}$ or in non-standard employment, ${ }^{40}$ which may reduce their life-time exposure to cognitively stimulating workrelated activities. For younger workers, transitions into nonstandard employment during economic downturns are more likely than for older workers. ${ }^{40}$ This may account for the stronger association of early life and mid-life recessions with late-life cognitive function among women, while recessions experienced at ages 45-49 were not associated with cognitive function.

Our findings suggest that, among men, economic recessions in the later stages of mid adulthood (ages 45-49) are critically linked to lower cognitive function after age 50, potentially due to the effect of recessions at these ages on the risk of job loss. Although young workers faced with a major recession may suffer long-lasting reductions in earnings and reduced labour market opportunities, ${ }^{15}$ they are likely to return to work as economic conditions improve. ${ }^{40}$ In contrast, for older workers job loss in the late stages of their working career may become an involuntary 'pathway to retirement', with older workers often leaving the labour market permanently during economic downturns $^{41}$ or after involuntary job loss ${ }^{42}$ with reduced access to cognitively stimulating activities. This may explain why recessions in late-adulthood lead to larger reductions in cognitive function at older age, but not for early adulthood and midadulthood recessions. An alternative pathway may lead from job loss to depressive symptoms and stress, which in turn are associated with reduced cognitive function in older ages. ${ }^{43}$ The fact that economic recessions in later stages of adulthood were linked to cognitive function in men, but not in women, may stem from gender differences in occupational mobility. Previous research suggests that occupational mobility and associated wage gains are larger for men than for women. ${ }^{44}$ Mid-life working careers of women have been and still are largely different from those of men, and women during middle age may be out of the labour market more often than men for different reasons. ${ }^{45}$ Thus, a potential explanation is that recession effects on occupational mobility affect men more than they affect women. As a result, men who experience less favourable economic conditions in late mid-adulthood may accumulate less cognitive reserve as they approach older age.

The association between one additional recession and cognitive functioning (women $b_{25-34}=-0.03 ; b_{35-44}=-0.02 ;$ men $\left.\mathrm{b}_{45-49}=-0.06\right)$ may seem relatively small compared to associations between cognitive function and other indicators, for example, with higher education (women $b_{\text {secondary education }}=0.22$; men $b_{\text {secondary education }}=0.18$ ). However, the association between one additional recession and cognitive function has a similar magnitude as one additional year of age with cognitive decline after age 60 (both sexes after age $60 \mathrm{~b}_{\text {age splines }}=-0.01$ to -0.04 ).

\section{Limitations}

The main strength of our study was the linkage between individual-level data on work histories, cognitive function and macroeconomic shocks across European countries. However, several limitations should be considered. The first and most prominent limitation of our study is the fact that the abatement of selection, which we addressed by investigating the relationship between macroeconomic conditions and cognitive function, is no proof for causality. However, our results provide tentative support for the hypothesis that economic recessions are associated with cognitive function possibly through changes in working conditions.

We investigated several mechanisms by which economic recessions may influence later-life cognitive function; however, more specific mechanisms such as reduced occupational complexity, social participation or earnings could not be assessed. A strength of our study is the possibility to examine the role of national economic conditions on cognitive function on the basis of comparable data across countries. However, we were unable to appropriately assess potential differences across countries in magnitude and societal impact of recessions. Our findings are only applicable for the cohorts working during the post-WWII period in the European countries under investigation. Part of our sample was born before WWII and had experienced a dramatic and highly adverse historical period during childhood 
and/or adolescence. This cohort may have been severely affected in terms of nutrition, parental affluence, family and social networks and quantity and quality of education before entering the work force. We addressed this by including a dummy for being born before, during or after the WWII, thus controlling for the effect of this shock on cognitive outcomes. Nevertheless, future studies are necessary to assess whether associations observed in our study might differ for cohorts differently affected by WWII.

\section{CONCLUSIONS}

To our knowledge, this is the first study to show that economic recessions experienced at vulnerable ages in early and mid adulthood are associated with lower cognitive function at older ages. Our findings also suggest that economic recessions during this period are associated with several labour market outcomes. If replicated, policies that encourage women to enter and remain attached to the labour market through early adulthood and midadulthood, such as policies on schooling, maternity leave and childcare support, may have unanticipated positive effects on female cognitive function. Similarly, policies that enable men to return to work or remain engaged in productive activities at age 45 and beyond may be important in accumulating cognitive reserve. Preliminary evidence presented in this article suggests that for older men, the later stages of their career may be more prone to economic recessions and, in turn, offer greater potential to increase cognitive reserve than earlier stages. More evidence is needed to assess whether specific policies that buffer the impact of economic downturns on labour market outcomes bring benefits to cognitive functioning in older age.

\section{What is already known on this subject}

- Labour market engagement and stimulating working environments increase cognitive reserve and predict better cognitive function at older age.

- Fluctuations in the national economy shape labour market opportunities and outcomes, but the link between economic fluctuations during working ages and cognitive function in later ages has not yet been established.

\section{What this study adds}

- Economic recessions experienced at vulnerable ages in mid adulthood are associated with lower cognitive function at older ages.

- Recessions during mid-life are associated with cognitive function in older age, possibly through their impact on the likelihood of job loss for men as well as women and the lower likelihood of labour market engagement and downward occupational mobility among women.

- If findings are replicated, policies that encourage women to enter and remain attached to the labour market through early adulthood and mid-adulthood, and policies that enable men to return to work or remain engaged in productive activities during the late stages of their career may bring benefits to cognitive functioning in older age.
Contributors All authors were involved in design and conceptualisation of the study. AL is the principal investigator, she wrote the draft of the article. PH contributed to the draft, analysed the data and revised the draft. MA contributed to the draft, suggested supplementary analyses and revised the draft. All authors were involved in analysis and interpretation of the findings. All authors approved the final version of the article.

Funding $\mathrm{AL}$ is supported by the National Research Fund Luxembourg under the FLARE 2 programme (grant INTER/FLARE2/10/01). MA and PH are supported by a Starting Researcher grant from the European Research Council (ERC) (grant No 263684). Mauricio Avendano is additionally supported by National Institute of Ageing (grants R01AG037398 and R01AG040248) and the MacArthur Foundation Research Network on an Aging Society. Philipp Hessel is additionally supported by the Economic and Social Research Council (ESRC).

\section{Competing interests None.}

Ethics approval Ethical standards committee on human experimentation, Mannheim, Germany (IRB).

Provenance and peer review Not commissioned; externally peer reviewed.

\section{REFERENCES}

1 Dartigues JF, Gagnon M, Letenneur L, et al. Principal lifetime occupation and cognitive impairment in a French elderly cohort (Paquid). Am J Epidemiol 1992;135:981-8.

2 Jorm $A F$, Rodgers $B$, Henderson $A S$, et al. Occupation type as a predictor of cognitive decline and dementia in old age. Age Ageing 1998;27:477-83.

3 Li C-Y, Wu SC, Sung F-C. Lifetime principal occupation and risk of cognitive impairment among the elderly. Ind Health 2002;40:7-13.

4 Stern $Y$, Albert $S$, Tang $M X$, et al. Rate of memory decline in $A D$ is related to education and occupation: cognitive reserve? Neurology 1999;53:1942-7.

5 Virtanen M, Singh-Manoux A, Ferrie JE, et al. Long working hours and cognitive function: the Whitehall II Study. Am J Epidemiol 2009;169:596-605.

6 Andel R, Vigen C, Mack WJ, et al. The effect of education and occupational complexity on rate of cognitive decline in Alzheimer's patients. J Int Neuropsychol Soc 2006;12:147-52.

7 Bickel H, Kurz A. Education, occupation, and dementia: the Bavarian school sisters study. Dement Geriatr Cogn Disord 2009;27:548-56.

8 Kröger $E$, Andel R, Lindsay J, et al. Is complexity of work associated with risk of dementia?: The Canadian Study of Health and Aging. Am J Epidemiol 2008;167:820-30.

9 Stern Y, Alexander GE, Prohovnik I, et al. Relationship between lifetime occupation and parietal flow: implications for a reserve against Alzheimer's disease pathology. Neurology 1995;45:55-60.

10 Finkel D, Andel R, Gatz M, et al. The role of occupational complexity in trajectories of cognitive aging before and after retirement. Psychol Aging 2009;24:563.

11 Stern Y. What is cognitive reserve? Theory and research application of the reserve concept. J Int Neuropsychol Soc 2002:8:448-60.

12 Richards $M$, Sacker A. Lifetime antecedents of cognitive reserve. J Clin Exp Neuropsychol 2003;25:614-24.

13 Van den Berg GJ, Deeg DJ, Lindeboom M, et al. The role of early-life conditions in the cognitive decline due to adverse events later in life*. Econ J 2010;120:F411-28.

14 Doblhammer G, van den Berg GJ, Fritze T. Economic conditions at the time of birth and cognitive abilities late in life: evidence from eleven European countries. PLOS ONE 2013;8:e74915.

15 Oreopoulos $P$, von Wachter $T$, Heisz $A$. The short- and long-term career effects of graduating in a recession. Am Econ J App/ Econ 2012;4:1-29.

16 Kahn LB. The long-term labor market consequences of graduating from college in a bad economy. Labour Econ 2010;17:303-16.

17 Raaum 0, Røed K. Do business cycle conditions at the time of labor market entry affect future employment prospects? Rev Econ Stat 2006;88:193-210.

18 Ben-Shlomo Y, Kuh D. A life course approach to chronic disease epidemiology: conceptual models, empirical challenges and interdisciplinary perspectives. Int $\mathrm{J}$ Epidemiol 2002;31:285-93.

19 Börsch-Supan A, Jürges H. The Survey of Health, Ageing and Retirement in Europe — methodology. Mannheim: Mannheim Research Institute for the Economics of Ageing (MEA), 2005

20 Börsch-Supan A, Schröder M. Retrospective data collection in the Survey of Health, Ageing and Retirement in Europe. Retrospective data collection in the survey of health, ageing and retirement in europe. Mannheim: Mannheim Research Institute for the Economics of Ageing (MEA), 2011

21 Börsch-Supan A, Schröder M. Employment and health at 50+: an introduction to a life history approach to european welfare state interventions. The individual and the welfare state life histories in europe. Heidelberg: Springer, 2011.

22 Schröder M. Retrospective data collection in the Survey of Health, Ageing and Retirement in Europe. SHARELIFE methodology. Mannheim: Mannheim Research Institute for the Economics of Ageing (MEA), 2011. 
23 Börsch-Supan A, Brandt M, Hunkler C, et al. Data resource profile: the Survey of Health, Ageing and Retirement in Europe (SHARE). Int J Epidemiol 2013;42:992-1001.

24 Blane DB. Collecting retrospective data: development of a reliable method and a pilot study of its use. Soc Sci Med 1996;42:751-7.

25 Lee $\mathrm{S}$, Kawachi I, Berkman LF, et al. Education, other socioeconomic indicators, and cognitive function. Am J Epidemiol 2003;157:712-20.

26 Dewey ME, Prince MJ. Cognitive function. Health, Ageing and Retirement in Europe -First Results from the Survey of Health, Ageing and Retirement in Europe. Börsch-Supan A. et al. Mannheim: MEA, 2005.

27 Ofstedal MB, Fisher GG, Herzog RA. Documentation of cognitive functioning measures in the Health and Retirement Study. HRS Documentation Report DR-006 [online].

28 Federico G. The world economy 0-2000 AD: a review article. Eur Rev Econ Hist 2002;6:111-20.

29 Hodrick RJ, Prescott EC. Postwar U.S. Business Cycles: an empirical investigation. J Money Credit Banking 1997:29:1-16.

30 Hessel $\mathrm{P}$, Avendano $\mathrm{M}$. Are economic recessions at the time of leaving school associated with worse physical functioning in later life? Ann Epidemiol 2013. doi:10.1016/j.annepidem.2013.08.001.

31 UNESCO International Classification of Education.

32 ILO International Standard Classification of Occupation. Major, minor and unit groups.

33 De Luca G, Claudio R. Weights in the first three waves of SHARE. SHARE Release Guide 250 Waves 1 \& 2. Mannheim Research Institute for the Economics of Aging, 2011.

34 Aneshensel CS, Ko MJ, Chodosh J, et al. The urban neighborhood and cognitive functioning in late middle age. J Health Soc Behav 2011;52:163-79.
35 Clarke PJ, Ailshire JA, House JS, et al. Cognitive function in the community setting: the neighbourhood as a source of 'cognitive reserve'? J Epidemiol Community Health 2012;66:730-6.

36 Glymour MM, Kawachi I, Jencks CS, et al. Does childhood schooling affect old age memory or mental status? Using state schooling laws as natural experiments. $J$ Epidemiol Community Health 2008;62:532-7.

37 Rohwedder S, Willis RJ. Mental retirement. J Econ Perspect 2010;24:119-38.

38 Coe NB, von Gaudecker H-M, Lindeboom M, et al. The effect of retirement on cognitive functioning. Health Economics 2012;21:913-27.

39 Thévenon 0. Increased women's labour force participation in Europe: Progress in the work-life balance or polarization of behaviours? Population 64:235-72.

40 Leschke J. Has the economic crisis contributed to more segmentation in labour market and welfare outcomes? Working paper 2012.02. Brussels: European Trade Union Institute, 2012.

41 Coile CC, Levine PB. Labor market shocks and retirement: Do government programs matter? J Public Econ 2007;91:1902-19.

42 Flippen C, Tienda M. Pathways to retirement: patterns of labor force participation and labor market exit among the pre-retirement population by race, Hispanic origin, and sex. J Gerontol B Psychol Sci Soc Sci 2000;55:S14-27.

43 Chodosh J, Kado DM, Seeman TE, et al. Depressive symptoms as a predictor of cognitive decline: MacArthur Studies of Successful Aging. Am J Geriatr Psychiatry 2007;15:406-15

44 Fitzenberger B, Kunze A. Vocational training and gender: Wages and occupational mobility among young workers. Oxf Rev Econ Policy 2005;21:392-415.

45 Blossfeld H, Hofmeister H. Globalization, uncertainty and women's careers. Edward Elgar Publishing, 2006. 